\title{
Analytical method development and validation for the estimation of Naproxen using RP-HPLC
}

\author{
Akiful haque, S.Hasan Amrohi*, Mahesh Nasare, Prashanth Kumar.K, Pradeep \\ Kumar.T, Nivedita.G, Prakash V Diwan \\ School of Pharmacy, Anurag Group Of Institutions, Venkatapur, Ghatkesar, R.R, \\ Hyderabad, A.P, India.501301.
}

\begin{abstract}
Abstarct-A sensitive and specific isocratic RP-HPLC was developed for quantitative estimation of naproxen in Tablet formulation. Naproxen is chemically (+)-(S)-2-(6-methoxynaphthalen-2-yl) propanoic acid. Naproxen is a non steroidal anti-inflammatory drug (NSAID) with analgesic and antipyretic properties. Both the acid and its sodium salt are used in the treatment of rheumatoid arthritis and other rheumatic or musculoskeletal disorders, dysmenorrhea and acute gout. The developed method consist of mobile phase Phosphate Buffer and Methanol in (40:60) with isocratic programming, Symmetry $C_{18}, 250 \times 4.6 \mathrm{~mm}, 5 \mu \mathrm{m}$ column as stationary phase with a flow rate of $1.3 \mathrm{ml} /$ minute. Proposed method was found to be linear in the concentration range of 2 to 20 ppm levels, the correlation coefficient was found to be 0.999. System suitability parameters were studied by injecting the standard solution five times and results were well under the acceptance criteria, the proposed method is found to be sensitive, rapid, reproducible, and accurate. Keywords--Naproxen, RP-HPLC, stationary phase.
\end{abstract}

\section{INTRODUCTION}

The compound (+)-(S)-2-(6-methoxynaphthalen-2-yl) propanoic acid (Naproxen) is a member of Cyclooxygenase Inhibitors. Naproxen (marketed as Artagen $^{\circledR}$, Arthopan ${ }^{\circledR}$, and Napexar ${ }^{\circledR}$ ) manufactured by Ranbaxy. Naproxen is a non steroidal anti-inflammatory drug (NSAID) with analgesic and antipyretic properties. The mechanism of action of naproxen, like that of other NSAIDs, is believed to be associated with the inhibition of Cyclooxygenase activity. Inhibition of COX-1 is thought to be associated with gastrointestinal and renal toxicity while inhibition of COX-2 provides anti-inflammatory activity. Naproxen is used to relieve pain from various conditions such as headaches, muscle aches, tendonitis, dental pain, and menstrual cramps. It also reduces pain, swelling, and joint stiffness caused by arthritis, bursitis, and gout attacks.

\section{LITERATURE REVIEW}

Lotfi Monser at al., developed a simple, selective and sensitive high performance liquid chromatographic (HPLC) method for the simultaneous determination of naproxen and its main degradation products such as 1-(6-methoxy-2-naphthyl) ethanol (MNE), 2-methoxy-6-ethyl naphthalene (MEN) and 2acetyl-6-methoxy naphthalene (AMN). The separation of these compounds was achieved on porous graphitic carbon (PGC) column using tetrahydrofuran-methanol as the mobile phase, and the effluent from the column was monitored at $272 \mathrm{~nm}$. At a flow rate of $1 \mathrm{ml} \mathrm{min}^{-1}$, the retention time of the last eluting compound was less than $10 \mathrm{~min}$. Correlation coefficient for calibration curves in the ranges 2-25 $\mu \mathrm{g} \mathrm{ml}{ }^{-1}$ for all compounds studied were greater than 0.999 . The sensitivity of detection is $0.05 \mu \mathrm{g} \mathrm{l}^{-1}$ for naproxen, MNE and MEN and $0.20 \mu \mathrm{g}$ $\mathrm{ml}^{-1}$ for AMN. The reproducibility of the peak area of these compounds using isocratic elution were quite high, and the standard deviations (S.D.) were below $2 \%(n=5)$. The reproducibility of retention times of these compounds was within $1 \%(n=5)$. The proposed liquid chromatographic method was successfully applied to the analysis of commercially available naproxen sodium (NS) dosage forms with recoveries of $98.8-102 \%$. A comparative study shows that the selectivity of these compounds on PGC column was different to that obtained with octadecyl silica (ODS) columns.

Patricia Damiani at al., reported a rapid, selective, sensitive and simple fluorescence method for the direct determination of naproxen in tablets. The tablets were triturated, dissolved in either $\mathrm{NH}_{3}$ or $\mathrm{NaOH}$ solution, sonicated, filtered and then direct fluorescence emission was read at $353 \mathrm{~nm}$ (exciting at $271 \mathrm{~nm}$ ). In order to validate the method the results were compared with those obtained by the USP XXIV NF 19 Pharmacopeia reference method (high performance liquid chromatography). The slope, intercept and variances which are associated with the regression coefficient calculated with bivariate least square (BLS) regression indicate that both methods are statistically comparable. The recoveries were excellent, except in tablets containing the antibiotic tetracycline. In this latter case a correction procedure is necessary. 
Islam Ullah Khan et al., reported that Naproxen reacts with 1-naphthylamine and sodium nitrite to give an orangish red color having maximum absorbance at 460-480 nm (working wavelength $480 \mathrm{~nm}$ ). The reaction is selective for naproxen with $0.001 \mathrm{mg} / \mathrm{ml}$ as visual limit of quantitation and provides a basis for a new spectrophotometric determination. The reaction obeys Beer's law from $0.01 \mathrm{mg}$ to $6.5 \mathrm{mg} / 10 \mathrm{ml}$ of naproxen and the relative standard deviation is $1.5 \%$. The quantitative assessment of tolerable amount of other drugs is also studied.

Rajesh Nuni, A reverse phase HPLC method is developed for the determination of Sumatriptan and naproxen in pharmaceutical dosage forms. Chromatography was carried out on a C8 column $[4.6 \mathrm{x} 150 \mathrm{~mm}$, $3.5 \mathrm{~mm}$, Make: XTerra] using a mixture of potassium di hydrogen ortho phosphate buffer and acetonitrile (50:50 $\mathrm{v} / \mathrm{v}$ ) as the mobile phase at a flow rate of $0.7 \mathrm{ml} / \mathrm{min}$. Detection was carried out at $285 \mathrm{~nm}$. The retention time of the drug Naproxen and sumatriptan was 2.24 minand $5.871 \mathrm{~min}$. The method produced linear responses in the concentration range of 60 to $100 \mu \mathrm{g} / \mathrm{ml}$ of Sumatriptan and naproxen. The LOD values for HPLC method for naproxen and sumatriptan were found to be 3.20 and $3.36 \mathrm{ng} / \mathrm{ml}$. The LOQ for Naproxn and Sumatriptan were foud to be 9.86 and $9.90 \mathrm{ng} / \mathrm{ml}$ respectively. The method was found to be applicable for determination of the drug in tablets.

\section{DRUG PROFILE OF NAPROXEN}

Naproxen is a non steroidal anti-inflammatory drug (NSAID) with analgesic and antipyretic properties. Both the acid and its sodium salt are used in the treatment of rheumatoid arthritis and other rheumatic or musculoskeletal disorders, dysmenorrhea and acute gout.
Structure

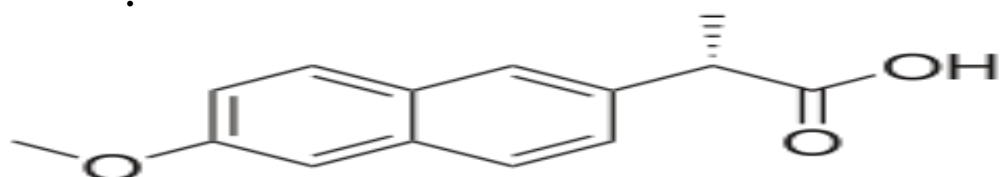

\section{Formula \\ Category}
Systematic IUPAC name
Gout Suppressants
Physical state
Solubility
Melting point
Molecular Weight
: (+)-(S)-2-(6-methoxynaphthalen-2-yl) propanoic acid
: $\mathrm{C}_{14} \mathrm{H}_{14} \mathrm{O}_{3}$
: Cyclooxygenase Inhibitors
: Solid (Powdered solid and crystalline powder)
: Insoluble in cold water
: $152^{\circ} \mathrm{C}\left(305.6^{\circ} \mathrm{F}\right)$
: $230.26 \mathrm{~g} / \mathrm{mole}$

\section{MECHANISM OF ACTION}

The mechanism of action of naproxen, like that of other NSAIDs, is believed to be associated with the inhibition of Cyclooxygenase activity. Two unique Cyclooxygenases have been described in mammals. The constitutive Cyclooxygenase, COX-1, synthesizes prostaglandins necessary for normal gastrointestinal and renal function. The inducible Cyclooxygenase, $\mathrm{COX}-2$, generates prostaglandins involved in inflammation. Inhibition of COX-1 is thought to be associated with gastrointestinal and renal toxicity while inhibition of COX-2 provides anti-inflammatory activity.

\section{Pharmacokinetic data}

Bioavailability: Naproxen itself is rapidly and completely absorbed from the GI tract with an in vivo bioavailability of $95 \%$. Although naproxen itself is well absorbed, the sodium salt form is more rapidly absorbed resulting in higher peak plasma levels for a given dose. Food causes a slight decrease in the rate absorption.

Protein binding: At therapeutic levels naproxen is greater than $99 \%$ albumin-bound.

Metabolism: Naproxen is extensively metabolized to 6-0-desmethyl naproxen and both Parent and metabolites do not induce metabolizing enzymes.

Half life: The observed terminal elimination half-life is approximately 15 hours.

Excretion: The clearance of naproxen is $0.13 \mathrm{~mL} / \mathrm{kg}$. Approximately $95 \%$ of the naproxen from any dose is excreted in the urine, primarily as naproxen(Less than 4\%), 6-0-desmethyl naproxen (less than 1\%) or their conjugates $(66 \%-92 \%)$.

Clinical use:Naproxen is used to relieve pain from various conditions such as headaches, muscle aches, tendonitis, dental pain, and menstrual cramps. It also reduces pain, swelling, and joint stiffness caused by arthritis, bursitis, and gout attacks.

Adverse Effects: Naproxen has side effects similar to other NSAIDs. A 2011 meta-analysis published in the British Medical Journal states that, of all NSAIDs evaluated, naproxen was associated with the smallest overall cardiovascular risks. As with other NSAIDs, naproxen can cause gastrointestinal problems such as 
heartburn, constipation, diarrhea, ulcers, and stomach bleeding. It may interfere and reduce the efficiency of SSRI antidepressants

\section{OBJECTIVE}

The Literature survey indicates that there are very few methods for the determination of Naproxen. Therefore an attempt was made to develop and validate a simple and economical RP-HPLC method as per ICH guidelines for the estimation of Naproxen in pharmaceutical dosage forms.

\section{EQUIPMENTS AND CHEMICALS}

A simple reverse phase HPLC method was developed for the determination of Naproxen pharmaceutical dosage form of $400 \mathrm{mg}$. column used kromosil $(150 * 4.6 \mu \mathrm{m}$ packed with $5 \mu \mathrm{m})$ in an isocratic mode with mobile phase Buffer: Methanol (40:60) was used. The flow rate was $1.3 \mathrm{ml} / \mathrm{min}$ and effluent was monitored at $266 \mathrm{~nm}$ and column temperature of $25^{\circ} \mathrm{C}$.

\section{Equipment and Apparatus used:}

1. HPLC with PDA detector (Waters)

2. Sonicator (Ultrasonic sonicator)

3. $\quad \mathrm{P}^{\mathrm{H}}$ meter (Thermo scientific)

4. Micro balance (Sartorius)

5. Vacuum filter pump

Reagents used:

1. Methanol HPLC Grade (RANKEM)

2. Acetonitrile HPLC Grade (RANKEM)

3. HPLC grade Water (RANKEM)

4. Glacial Acetic acid

\section{Optimized conditions}

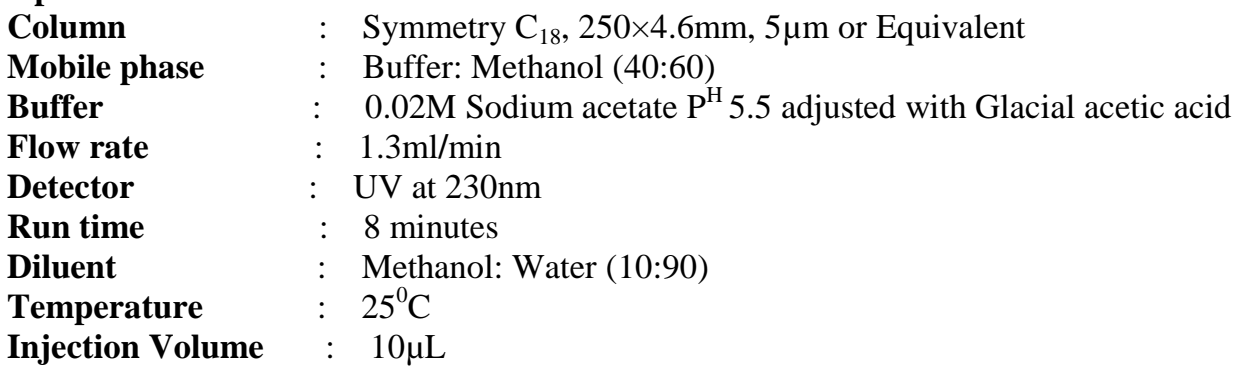

Preparation of Mobile phase:

Mobile Phase: Phosphate Buffer: Methanol (40:60)

\section{Buffer Preparation:}

$2.999 \mathrm{gms}$ of ammonium acetate and $2 \mathrm{ml}$ of triethyl amine in $1000 \mathrm{ml}$ of water and adjust the $\mathrm{P}^{\mathrm{H}}$ to 6.5 using orthophosphoric acid.

Stock and Standard Solution Preparation: $100 \mathrm{microgram} / \mathrm{ml}$

Weigh accurately about 10mg Naproxen working standard and transfer into a $100 \mathrm{~mL}$ volumetric flask, add 70 $\mathrm{mL}$ of diluent and sonicate to dissolve for about $5 \mathrm{~min}$ solution was filtered through $0.45 \mu$ filter, further volume was made up with diluent (Stock Solution). From this solution $2 \mathrm{~m}$ was taken in 10 volumetric flask and volume made up with diluent (Standard Solution 20ppm)

\section{Preparation of Linearity Solutions}

By appropriate aliquots of the standard naproxen solution with mobile phase, five working solutions ranging between 2-20 ppm were prepared. Each experiment was performed in triplicate according to optimized chromatographic conditions. The peak areas of the chromatograms were plotted against the concentration of naproxen to obtain the calibration curve.

\section{Sample Preparation:}


20 tablets were weighed and crushed into powder. Weighed powder equivalent to $5 \mathrm{mg}$ of the naproxen transferred into a $100 \mathrm{~mL}$. Volumetric flask, $70 \mathrm{~mL}$ of diluent added and sonicated for $15 \mathrm{~min}$, further volume was made up with diluent. Solution was filtered through $0.45 \mu$ Nylon filter. $4 \mathrm{ml}$ of this solution was transferred to $10 \mathrm{ml}$ volumetric flask and volume was made up with diluent.

\section{SYSTEM SUITABILITY}

A Standard solution of Naproxen working standard was prepared as per procedure and was injected five times into the HPLC system. The system suitability parameters were evaluated from standard Chromatograms obtained by calculating the \% RSD of retention times, tailing factor, theoretical plates and peak areas from five replicate injections.

\section{LINEARITY}

To demonstrate the linearity of assay method, inject 5 standard solutions with concentrations of about $2 \mathrm{ppm}$ to $20 \mathrm{ppm}$ of Naproxen. Plot a graph to concentration versus peak area. The results were summarised in table $1 \& 2$.

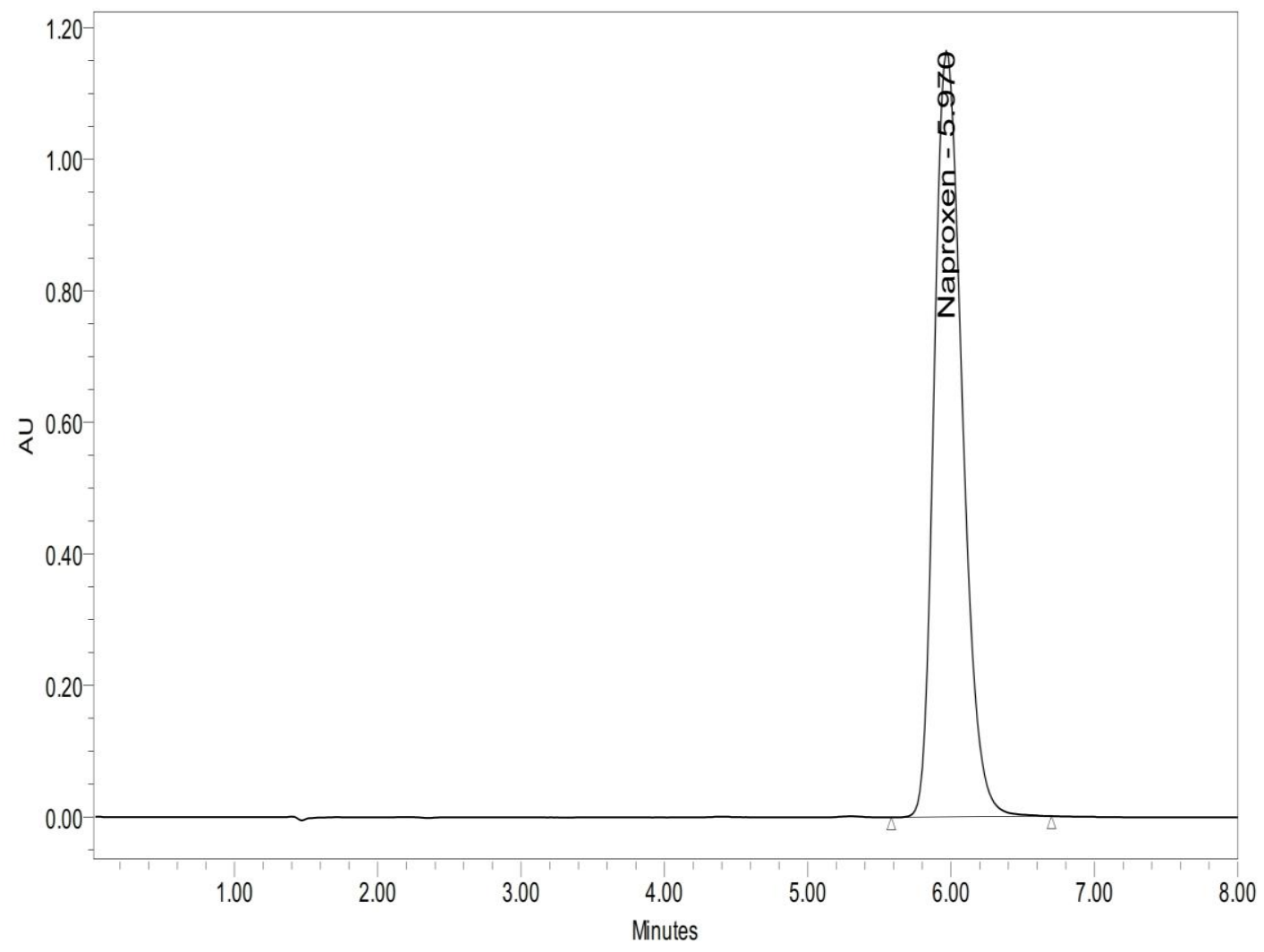

Fig No: 1 Chromatogram of standard naproxen 


\section{ASSAY OF MARKETED FORMULATION}

Standard solution and sample solution were injected separately into the system and chromatograms were recorded and drug present in sample was calculated using afore mentioned formula.

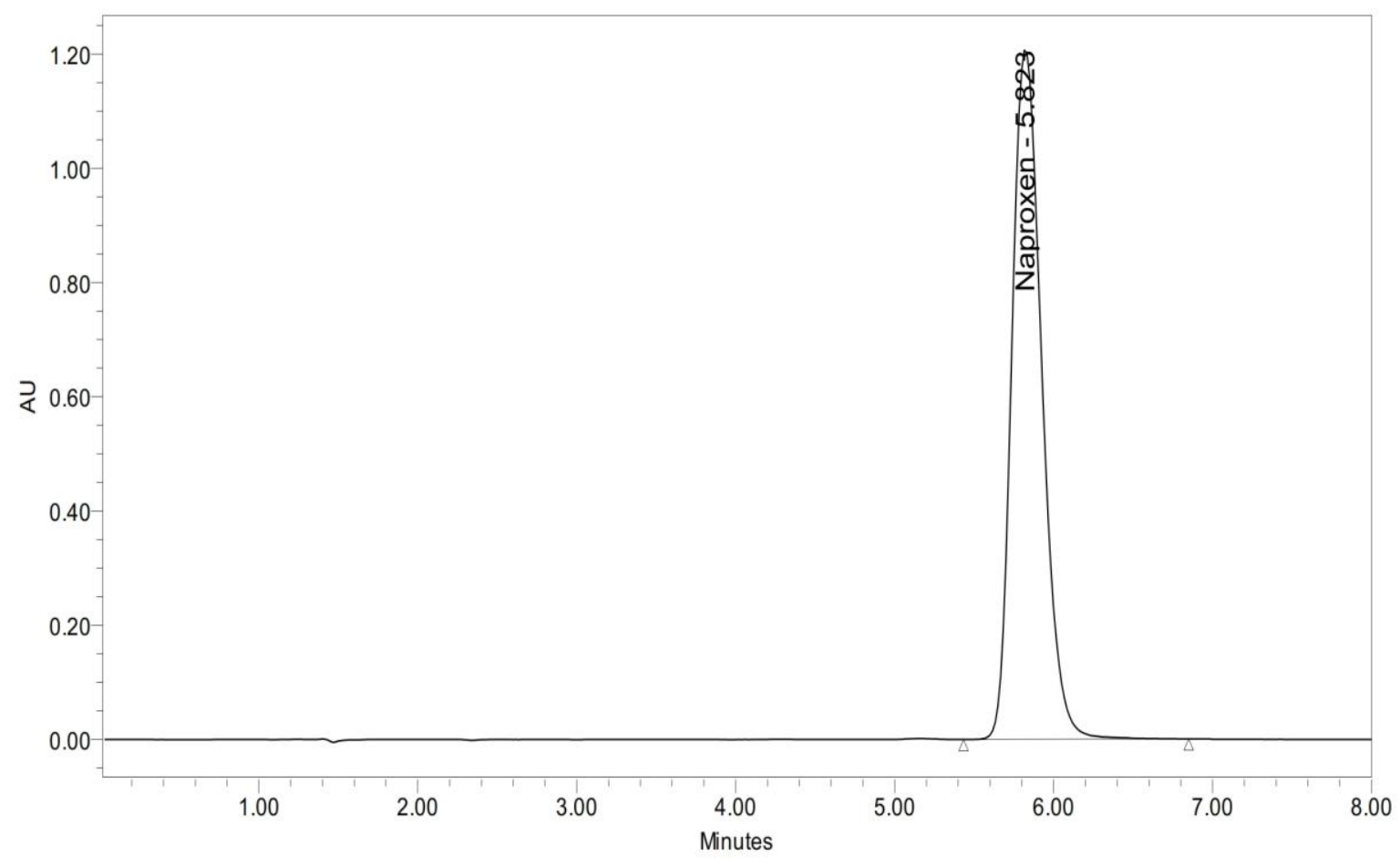

Fig No: 2 Chromatogram of Formulation

\section{RESULTS AND DISCUSSIONS}

Naproxen is the drug mainly used to an anti-inflammatory agent with analgesic and antipyretic. A simple reverse phase HPLC method was developed for the determination of Naproxen. Column (250 x $4.6 \mathrm{~mm}$, packed with $5 \mu \mathrm{m})$ in an isocratic mode with mobile phase Phosphate Buffer: Methanol (40:60) was used. The flow rate was $1.3 \mathrm{ml} / \mathrm{min}$ and effluent was monitored at $230 \mathrm{~nm}$. The column temperature was $25^{\circ} \mathrm{C}$. The Retention time was found to be 5.82 .

\section{System Suitability Parameters}

\begin{tabular}{|l|l|l|l|l|}
\hline & Retention Times & Peak Area & Tailing Factor & Theoretical Plates \\
\hline 1 & 5.745 & 1625233 & 1.2 & 5770 \\
\hline 2 & 5.759 & 1606708 & 1.2 & 5707 \\
\hline 3 & 5.759 & 1588213 & 1.2 & 5288 \\
\hline Mean & 5.754 & 1606718 & - & - \\
\hline SD & 0.00808 & 18510 & - & - \\
\hline \%RSD & 0.14 & 1.152 & - & - \\
\hline
\end{tabular}

Table No: 1

\begin{tabular}{|l|l|l|}
\hline Linearity Level (\%) & Concentration $\mathbf{( p p m )}$ & Area \\
\hline 20 & 2 & 226723 \\
\hline 50 & 5 & 686907 \\
\hline 100 & 10 & 1591140 \\
\hline 120 & 12 & 1890941 \\
\hline 200 & 20 & 3239201 \\
\hline
\end{tabular}

Table No: 2 
Analytical method development and validation for the estimation of naproxen using rp-hplc

\begin{tabular}{|l|l|}
\hline \multicolumn{2}{|c|}{ Optimized characteristics for linearity of Naproxen by RP-HPLC } \\
\hline Parameters & Observed values \\
\hline Linearity concentration & $2-20 \mathrm{ppm}$ \\
\hline Slope & 16832 \\
\hline Intercept & -12257 \\
\hline Correlation coefficient & 0.999 \\
\hline
\end{tabular}

Table No: 3

\section{CONCLUSION}

Naproxen is the drug used in the treatment of AIDS. It is a potential Xanthine oxidase inhibitor. From literature review and solubility analysis initial chromatographic conditions were set and different trials were run to Naproxen get eluted with good peak symmetric properties. Mobile phase Phosphate buffer: Methanol (40:60), Column, Symmetry $\mathrm{C}_{18}, 250 \times 4.6 \mathrm{~mm}, 5 \mu \mathrm{m}$ and flow rate $1.3 \mathrm{ml} / \mathrm{min}$, detection wave length $230 \mathrm{~nm}$, column temperature $25^{\circ} \mathrm{c}$ and diluent Methanol: Water (50:50) conditions were finalized as optimized method. System suitability parameters were studied by injecting the standard five times and results were well under the acceptance criteria. Linearity study was carried out between 2 to $20 \mathrm{ppm}$ levels, $\mathrm{R}^{2}$ value found 0.999 . By using above method assay of marketed formulation was carried out, $99.7 \%$ was present. Full length method was not performed; if it is done this method can be used for routine analysis of Naproxen.

\section{BIBLIOGRAPHY}

[1]. Ewing G. W., Instrumental Methods of Chemical Analysis, McGraw Hill Publishing Company Ins., 2 nd Ed., $1960: 3$.

[2]. Lurie S. Ira and Wittwer, D. John Jr., HPLC in Forensic Chemistry, vii.

[3]. Skoog D. A., West D. M. and Holler F. J., Fundamentals of Analytical Chemistry, Saunders College Publishing, New York, 6th Ed., 713

[4]. Jeffery G. H., Bassett J., Medham J.and Denney R. C., Vogel's Textbook of Quantitative Chemical Analysis, English Language Book Society/ Longman, 5th Ed., $1989: 668$.

[5]. International Conference on Harmonization, Validation of Analytical Procedures: Methodology,Federal Register, Nov. 1996:1-8.

[6]. International Conference on Harmonization, Draft Guideline on Validation of Analytical Procedures, Definitions and Terminology, Federal Register (26), 1995: 11260.

[7]. United State Pharmacopoeia, Vol. I \& II, Asian edition, United Pharmacopoeial Convention, Inc., Rockville, $2000: 2149$.

[8]. United State Pharmacopoeia, Vol. I \& II, Asian edition, United Pharmacopoeial Convention, Inc., Rockville, $2000: 1923$.

[9]. Chatwal, G.R and anand, S.K., In; instrumental method of chemical analysis, $5^{\text {th }}$ Edn., 2005,2.107.

[10]. Sharma, B.K., In; instrumentalmethod of chemical analysis, $15^{\text {th }}$ Edn., 1996,453.

[11]. Beckett, A.H., and stenlake, J.B., Inpractical pharmaceutical chemistry, $4^{\text {th }}$ Edn, 2002,2,85.

[12]. Willard merit, H.H, Dean, Jr., and J.A., In; instrumental method of analysis, $6^{\text {th }}$ Edn., 1986, 504

[13]. Dr. Ravi Shankar. S., In; text book of pharmaceutical analysis, $3^{\text {rd }}$ Edn., 1999,13-1.

[14]. Remington the science and practice of pharmacy, $20^{\text {th }}$ edition, 2000, 1, 587.

[15]. Jen martens - lobenhoffer, j., and bode-boger, S.M., J chromatogr B analyt technol biomed life sci, 2005, may 5, 819(1),197.

[16]. Rao B.M., Ravi R., Shyamsundar reddy B., Sivakumar S., Gopichand, Praveen kumar, K., Acharyulu, P.V., Reddy, G.Om., aand Srinivasu, M.K., J pharm Biomed Anal, 2004, Aug 18,745(2), 325.

[17]. Tiegong Guo, Lisa Oswald, M., Damodar Rao Mendu, and StevenSolidin, J., Clin Chim Acta.2007, Jan 375(1-2) 115.

[18]. Chidambaram Saravanan et al, Method Development and Validation for Determination of Naproxen by UV Spectrophotometer, International Research Journal of Pharmacy, 1 (1), 2010, 314-323.

[19]. D. Ramakanth Reddy et al., Validated Spectrophotometric Method for Simultaneous estimation of Naproxen and Lamivudine in Combined Pharmaceutical dosage form International Journal of PharmTech Research, Vol.4, No.1, pp 311-314, Jan-Mar 2012.

[20]. B. Agaiah Goud et al., Quantitative Estimation of Naproxen by UV Spectrophotometry, International Journal Of Pharmacy \& Technology Dec-2010| Vol. 2 | Issue No.4| 1328-1333.

[21]. C. H. Sharada et al., Development of a Spectrophotometric Method for the Quantitative Estimation of Naproxen Concentration in Bulk and Pharmaceutical Dosage Forms, KMITL Sci. Tech. J. Vol. 10 No. 1 Jan. - Jun. 2010.

[22]. J. Nijamdeen et al., Method development and validation of RP-HPLC method for simultaneous determination of Lamivudine and Naproxen J. Chem. Pharm. Res., 2010, 2(3):92-96.

[23]. D. Anantha Kumar et al., Simultaneous Determination of Lamivudine, Naproxen and Nevirapine in Tablet Dosage Forms by RPHPLC Method, RASAYAN J. ChemVol.3, No.1 (2010), 94-99.

[24]. P. Venkatesh et al., Simultaneous estimation of Naproxen and Lamivudine tablets by RP-HPLC method, International Journal of Chem Tech Research, Vol. 3, No.1, pp 376-380, Jan-Mar 2011.

[25]. Maria Inês R. M. Santoro et al., Stability-Indicating Methods for Quantitative Determination of Naproxen and Stavudine in Capsule Quim. Nova, Vol. 29, No. 2, 240-244, 2006

[26]. K. Anand Babu et al., Analytical Method Development and Validation for Simultaneous Estimation of Naproxen, Lamivudine and Navirapine Tablets by RP-HPLC, International Journal of Pharmaceutical Research and Development, Vol 3 (7) Sep 2011, 9-14.

[27]. Nandini Pai, et al., Simultaneous reverse phase HPLC estimation of some antiretroviral drugs from tablets Indian Journal of Pharmaceutical Sciences. 2007, 69 (1). 118-120 